\title{
Diel fluctuations of viscosity-driven riparian inflow affect streamflow DOC concentration
}

\author{
Michael P. Schwab ${ }^{1,2, a}$, Julian Klaus ${ }^{1}$, Laurent Pfister ${ }^{1}$, and Markus Weiler ${ }^{2}$ \\ ${ }^{1}$ Catchment and Eco-Hydrology Research Group, Luxembourg Institute of Science and Technology, \\ 4422 Belvaux, Luxembourg \\ ${ }^{2}$ Hydrology, Faculty of Environment and Natural Resources, University of Freiburg, 79098 Freiburg, Germany \\ ${ }^{a}$ now at: Climate and Water Department, World Meteorological Organization (WMO), Geneva, Switzerland
}

Correspondence: Michael P. Schwab (mschwab@wmo.int)

Received: 30 June 2017 - Discussion started: 12 July 2017

Revised: 5 February 2018 - Accepted: 26 February 2018 - Published: 13 April 2018

\begin{abstract}
Diel fluctuations of stream water DOC concentrations are generally explained by a complex interplay of different instream processes. We measured the light absorption spectrum of water and DOC concentrations in situ and with high frequency by means of a UV-Vis spectrometer during 18 months at the outlet of a forested headwater catchment in Luxembourg $\left(0.45 \mathrm{~km}^{2}\right)$. We generally observed diel DOC fluctuations with a maximum in the afternoon during days that were not affected by rainfall-runoff events. We identified an increased inflow of terrestrial DOC to the stream in the afternoon, causing the DOC maxima in the stream. The terrestrial origin of the DOC was derived from the SUVA-254 (specific UV absorbance at $254 \mathrm{~nm}$ ) index, which is a good indicator for the aromaticity of DOC. In the studied catchment, the most likely process that can explain the diel DOC input variations towards the stream is the so-called viscosity effect. The water temperature in the upper parts of the saturated riparian zone is increasing during the day, leading to a lower viscosity and therefore a higher hydraulic conductivity. Consequently, more water from areas that are rich in terrestrial DOC passes through the saturated riparian zone and contributes to streamflow in the afternoon. We believe that not only diel instream processes, but also viscosity-driven diel fluctuations of terrestrial DOC input should be considered to explain diel DOC patterns in streams.
\end{abstract}

\section{Introduction}

Dissolved organic matter (DOM) is a major constituent of the carbon cycle and aquatic biogeochemistry, eventually linking terrestrial and aquatic ecosystems (Battin et al., 2008; Lee et al., 2016; Saraceno et al., 2009). The largest component of DOM in forested stream ecosystems is dissolved organic carbon (DOC; McLaughlin and Kaplan, 2013). DOC has a multifaceted chemical character that is mainly determined by its origin and its biogeochemical transformation (Hanley et al., 2013; Ruhala and Zarnetske, 2017). DOC in streams is mainly derived from external terrestrial sources (allochthonous) like plants and soils or from instream microbial sources (autochthonous). With increasing stream orders, autochthonous sources become more important (Dawson et al., 2001; Nimick et al., 2011). While DOC from allochthonous sources is characterized by fulvic and humic acids with high molecular weight and aromaticity, DOC from autochthonous sources has a lower molecular weight and is less aromatic (Hood et al., 2006; Saraceno et al., 2009; Spencer et al., 2012).

Different techniques have been used to gain information on the composition and the concentration of DOC. Two frequently used optical methods to characterize bulk DOC are UV-Vis spectroscopy and fluorescence spectroscopy (Minor et al., 2014). For identifying the aromaticity of DOC in aqueous systems, the specific UV absorbance at $254 \mathrm{~nm}$ (SUVA-254) is a commonly used index. SUVA-254 is calculated as the UV absorbance of water at the wavelength of $254 \mathrm{~nm}$ (A254) that is normalized for DOC concentration (Weishaar et al., 2003). A higher SUVA-254 value in- 
dicates a higher aromatic DOC content and is therefore a valuable index for distinguishing between allochthonous and autochthonous origins of DOC.

Several studies have used SUVA-254 to identify DOC from different origins in combination with changing contributions from different water sources and flow paths. Hood et al. (2006) observed an increase in SUVA-254 during a 6-day storm event in three catchments of the HJ Andrews Experimental Forest, Oregon (USA) and suggested SUVA254 as a useful tracer for identifying different flow paths through mineral soils. Also at HJ Andrews, Lee et al. (2016) observed lower SUVA-254 values during the dry season low flows and suggest, supported by fluorescence indices, that in those conditions the stream water originates from more microbial-processed sources. Fasching et al. (2016) described similar observations in an Austrian, alpine secondorder stream. They related the increase in SUVA-254 values during high flows mainly to a rise in terrestrial DOC contributions. Likewise, they correlated the decrease in SUVA254 values during baseflow conditions to larger contributions from autochthonous DOC sources. As an alternative, Catalán et al. (2013) identified seasonality as the main factor controlling SUVA-254 patterns in an ephemeral Mediterranean catchment because vegetation is accumulated during the dry period. In comparison to mechanistic studies focusing on seasonal and event timescales, investigations combining diel DOC fluctuations with SUVA-254 calculations are rather scarce. While Fasching et al. (2016) did not find clear diurnal SUVA-254 patterns in their stream, they were able to document diel DOC fluctuations with recurrent maxima around 19:30CET. They linked this pattern to a decrease in photosynthetically active radiation (PAR).

Diel DOC fluctuations in streams are generally explained by a complex interplay of different instream processes. They cannot be observed in every stream, but when they occur, DOC concentrations often increase during daytime and decrease at night (Nimick et al., 2011, and references therein). Throughout daytime, autotrophic organisms like algae excrete labile DOC during their photosynthesis, which depends on stream temperature and the amount of sunlight. In contrast, more instream DOC is consumed at night by heterotrophic organisms (Chittoor Viswanathan et al., 2015; Fasching et al., 2016; Nimick et al., 2011; Parker et al., 2010; Spencer et al., 2007). This interplay of autotrophic and heterotrophic organisms is generally used to explain diel DOC fluctuations in streams. Studies from catchments with peatlands have reported diel DOC fluctuations with DOC maxima in the early morning due to the absence of photic removal processes of DOC during the night (Worrall et al., 2015; Worrall and Moody, 2014). Tunaley et al. (2017) observed DOC maxima in the early morning for a peatland catchment, whereas a proximate catchment had its DOC maxima in the afternoon. Spencer et al. (2007) reported two DOC maxima per day in the San Joaquin River (California, USA).
In our study, we observed diel DOC concentration fluctuations at the outlet of a $0.45 \mathrm{~km}^{2}$ forested headwater catchment. During baseflow conditions throughout the year, the maximum diel DOC concentrations occurred in the afternoon. Based on our literature review of mechanistic explanations for DOC fluctuations, our first hypothesis states that diel fluctuations in DOC concentrations are mainly controlled by instream microbial processes. Our second hypothesis stipulates that diel fluctuations in DOC concentrations can be explained by an increased input of terrestrial DOC to the stream during daytime. This second hypothesis is a follow-up on previous work by Schwab et al. (2016) carried out in the Weierbach catchment. They linked diel fluctuations in discharge to increased inflow from the saturated riparian zone in the afternoon due to variations in viscosity (viscosity effect). Before the growing season, Schwab et al. (2016) observed diel discharge fluctuations with maxima in the afternoon that can be explained by riparian water temperature fluctuations and therefore viscosity fluctuations. Warmer riparian water temperatures in the afternoon led to a lower viscosity of water, resulting in a higher hydraulic conductivity and therefore an increasing inflow of water to the stream when passing through the saturated riparian zone. During the growing season, discharge minima were observed in the afternoon due to the stronger influence of evapotranspiration. Nevertheless, Schwab et al. (2016) concluded that the viscosity effect was still present during the growing season, but no longer visible in the diel discharge fluctuations as a result of the increased importance of the counteracting evapotranspiration. We intend to leverage these findings through our second hypothesis that the viscosity effect could possibly increase the input of terrestrial DOC in the afternoon all year long.

We used SUVA-254 to test both hypotheses. A decrease in SUVA-254 values during the afternoon would lead to the rejection of the second hypothesis that an augmented input of terrestrial DOC can explain the DOC concentration maxima in the stream. Increased SUVA-254 values would lead to the rejection of the first hypothesis, in which instream processes are presumed to control fluctuations in DOC concentrations.

\section{Study site and methods}

We measured the DOC concentration and the light absorption spectrum with a UV-Vis spectrometer in the Weierbach stream in Luxembourg from December 2013 to May 2015 (Fig. 1). The Weierbach is a headwater catchment with a size of $0.45 \mathrm{~km}^{2}$ and elevations ranging from 450 to $512 \mathrm{~m}$ a.s.l. Beech (Fagus sylvatica) and to a lesser extent spruce (Picea abies) are the dominant tree species in this forested catchment. The soils are shallow Cambisols with a depth generally less than $1 \mathrm{~m}$ and the bedrock geology consists of Devonian metamorphic slate and overlying Pleistocene periglacial slope deposits (Moragues-Quiroga et al., 2017). In the vicin- 


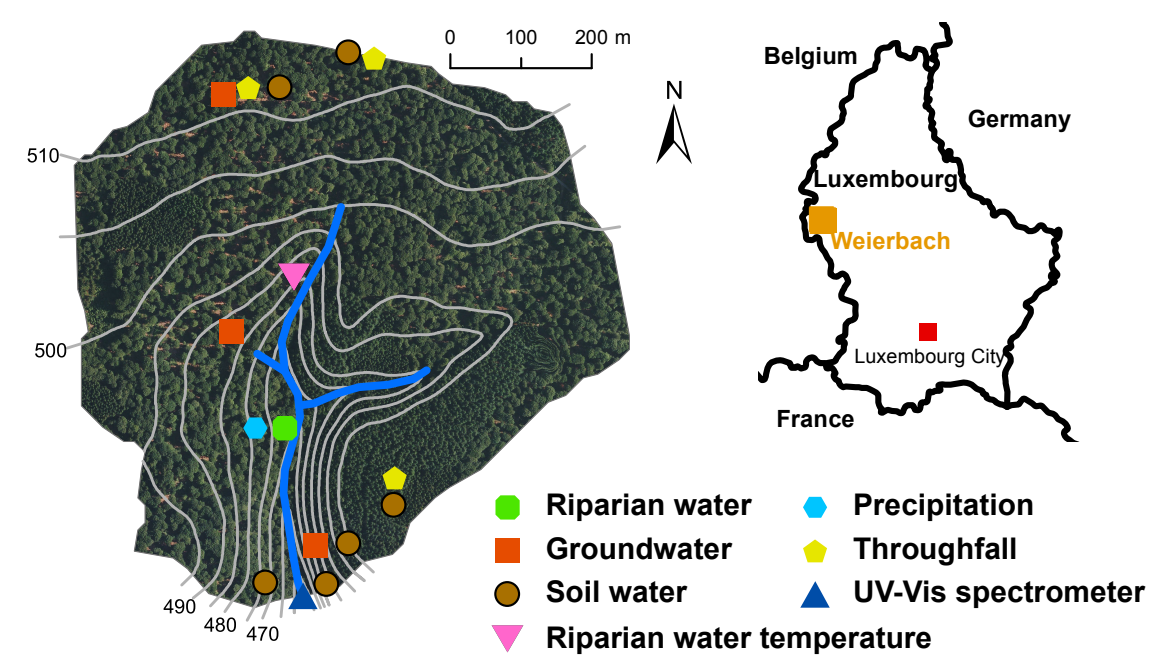

Figure 1. The Weierbach catchment: location of the spectrometer, the end-member sampling points and the measurement location of the riparian water temperature (modified from Schwab et al., 2017).

ity of the stream, the hillslopes are gentle on the right bank side and steep on the left bank side, while further uphill slopes tend to plateau. Along most parts of the stream a riparian zone extends 1 to $5 \mathrm{~m}$ away from the channel and connects the hillslopes to the stream. Water passing through the saturated riparian zone contributes significantly to discharge both during wet and dry conditions.

At the outlet of the Weierbach catchment, we measured water levels with a pressure transducer (ISCO 4120 Submerged Probe) at 5 min intervals. Water levels were converted into discharge via a rating curve. We corrected the temperature sensitivity of the probe according to the stream water temperature (Schwab et al., 2016). Precipitation was measured with a tipping bucket rain gauge at the meteorological station of Roodt, $3.5 \mathrm{~km}$ outside the Weierbach catchment. Precipitation had no distinct seasonality and the longterm annual average was approximately $950 \mathrm{~mm}$. During the observation period, no substantial snowfall was observed. The annual rainfall runoff ratio was around $50 \%$ with higher discharge volumes in winter than in summer (Glaser et al., 2016; Martínez-Carreras et al., 2015; Pfister et al., 2017; Schwab et al., 2016).

The Weierbach catchment exhibits a distinct rainfallrunoff behavior characterized by marked differences between dry and wet conditions. During dry conditions rainfall events trigger only one single discharge peak. During wet conditions an additional second discharge peak occurs with a delay of one to several days. The first discharge peak is probably caused by near-surface and near-stream runoff processes, while the second discharge peak is likely generated by "subsurface flow through the highly conductive saprolite layers" on the hillslopes (Glaser et al., 2016). This subsurface flow is initiated once a certain wetness threshold is reached in the catchment. DOC concentrations increased only during the first peaks. During wet conditions the DOC concentration in the stream was generally lower as more DOC-poor subsurface flow contributed to streamflow (Schwab et al., 2017). The behavior of DOC concentrations at seasonal and event timescales will not be analyzed in this study. We focus solely on diel fluctuations of DOC concentrations during days without rainfall events.

In one part of the riparian zone with high subsurface flow to the stream, we measured the riparian groundwater temperature every $30 \mathrm{~min}$ at $10 \mathrm{~cm}$ of depth (Fig. 1). We could only rely on one location with high-frequency riparian groundwater temperature data for the entire observation period. However, saturated riparian water temperature measurements along several profiles from previous years showed temperature fluctuations down to $15 \mathrm{~cm}$ of depth that were consistent with the fluctuations that we observed at the selected location (Schwab et al., 2016). Based on our highfrequency temperature measurements at this location we calculated the viscosity of the saturated riparian water according to the Vogel equation (Schwab et al., 2016; Vogel, 1921). An increase in water temperature by $5{ }^{\circ} \mathrm{C}$ leads to a decrease (given the observed temperature range of groundwater) in viscosity by 12 to $15 \%$ and therefore to an increase in hydraulic conductivity in the same range (Tipler and Mosca, 2008). We consider the riparian zone to be saturated during most of the year. In the vicinity of the temperature sensor, the soil was saturated during the whole observation period. The riparian zone extends 1 to $5 \mathrm{~m}$ from the stream and is up to $1 \mathrm{~m}$ deep. The stream flows on solid, rather impermeable, mostly unweathered slate bedrock. Hence, most of the groundwater enters the stream through the riparian zone 


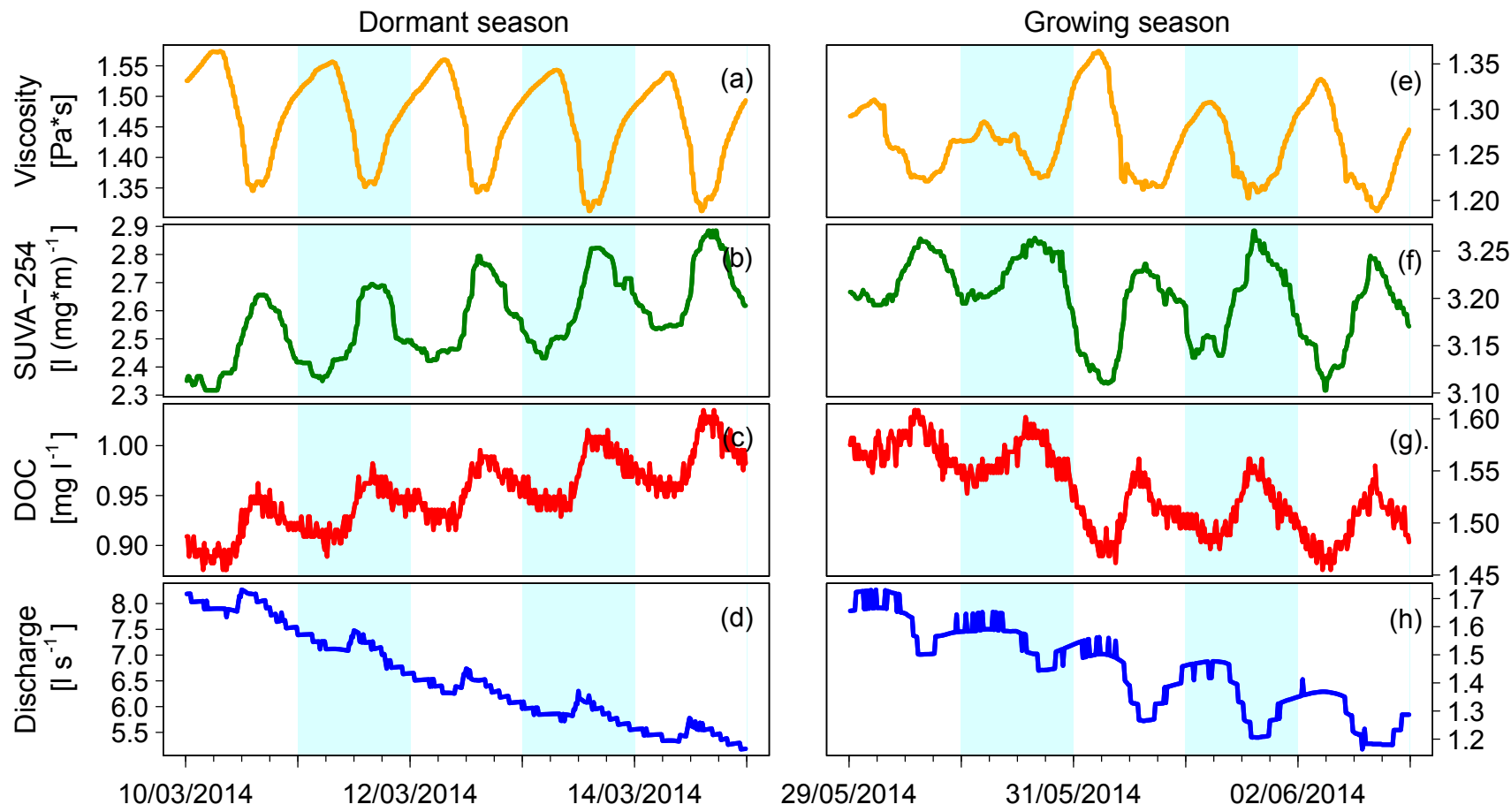

Figure 2. Diel fluctuations in the viscosity of saturated riparian water, SUVA-254, DOC and discharge during a representative rainless period in the dormant season and the growing season.

with hydraulic gradients from the riparian groundwater to the stream.

The DOC concentrations and the light absorption spectrum were measured in situ in the Weierbach stream (Fig. 1) at an interval of 15 min with the UV-Vis spectrometer spectro::lyser (s::can Messtechnik GmbH). The spectrometer measured the light absorption spectrum of the stream water between 220 and $720 \mathrm{~nm}$ in $2.5 \mathrm{~nm}$ resolution with a xenon flash lamp, 256 photo diodes and a two-beam instrument. The optical path length was $35 \mathrm{~mm}$. The spectrometer probe was fixed to a metal plate that was placed on the streambed of the Weierbach stream. The orientation of the probe was horizontal and in the stream direction with the measuring window facing the riverbed to avoid direct solar radiation. Every $3 \mathrm{~h}$, the measuring window of the spectrometer probe was cleaned automatically with pressurized air that was produced by an air compressor. We cleaned the spectrometer manually every 2 weeks.

We adapted the global calibration of the spectrometer that was provided by the manufacturer of the instrument to the local conditions by applying a local calibration. For this, we manually sampled the stream water weekly to biweekly and took automatic samples during several rainfall events. We analyzed the grab samples in the laboratory for DOC with a combustion analyzer (Apollo 9000; Teledyne Tekmar) and compared the results with the in situ DOC concentration measurements of the spectrometer at the collection time of the grab samples. The linear regression for the local cali- bration between the lab values and the spectrometer values resulted in a good fit with an $R^{2}$ of 0.96 . In the lab, we additionally measured SUVA-254 values of grab samples from the stream and compared them with in situ SUVA-254 values from the spectrometer. The linear regression between them resulted in a good fit with an $R^{2}$ of 0.74 .

A long time series of end-member chemistry data is available for the Weierbach catchment (Martínez-Carreras et al., 2015). DOC concentration values of biweekly sampled endmembers are available since 2009, while biweekly UV absorbance values at $254 \mathrm{~nm}$ (A254) are available since 2012 . The sampled end-members included throughfall, soil water, saturated riparian water and shallow groundwater. Throughfall was collected as bulk samples over 2 weeks at three different locations. Soil water was sampled by applying a vacuum to suction cups that were installed at six different locations in the soil at depths of 10 to $100 \mathrm{~cm}$. At one location in the riparian zone, saturated riparian water was collected with the same method. The biweekly grab samples of shallow groundwater were pumped from three wells in the catchment. The wells were screened for the lowest $50 \mathrm{~cm}$ to $1 \mathrm{~m}$ and had a depth of 2 to $3 \mathrm{~m}$ (Fig. 1).

SUVA-254 is a commonly applied index for characterizing the aromaticity and the terrestrial origin of DOC. SUVA-254 $\left(\mathrm{L} \mathrm{mg}^{-1} \mathrm{~m}^{-1}\right)$ is calculated as the $\mathrm{UV}$ absorbance at $254 \mathrm{~nm}$ (A254 in $\mathrm{m}^{-1}$ ) divided by the DOC concentration $\left(\mathrm{mg} \mathrm{L}^{-1}\right.$ ) (Weishaar et al., 2003). For the SUVA-254 data of the endmembers, A254 and the DOC concentrations of the biweekly 


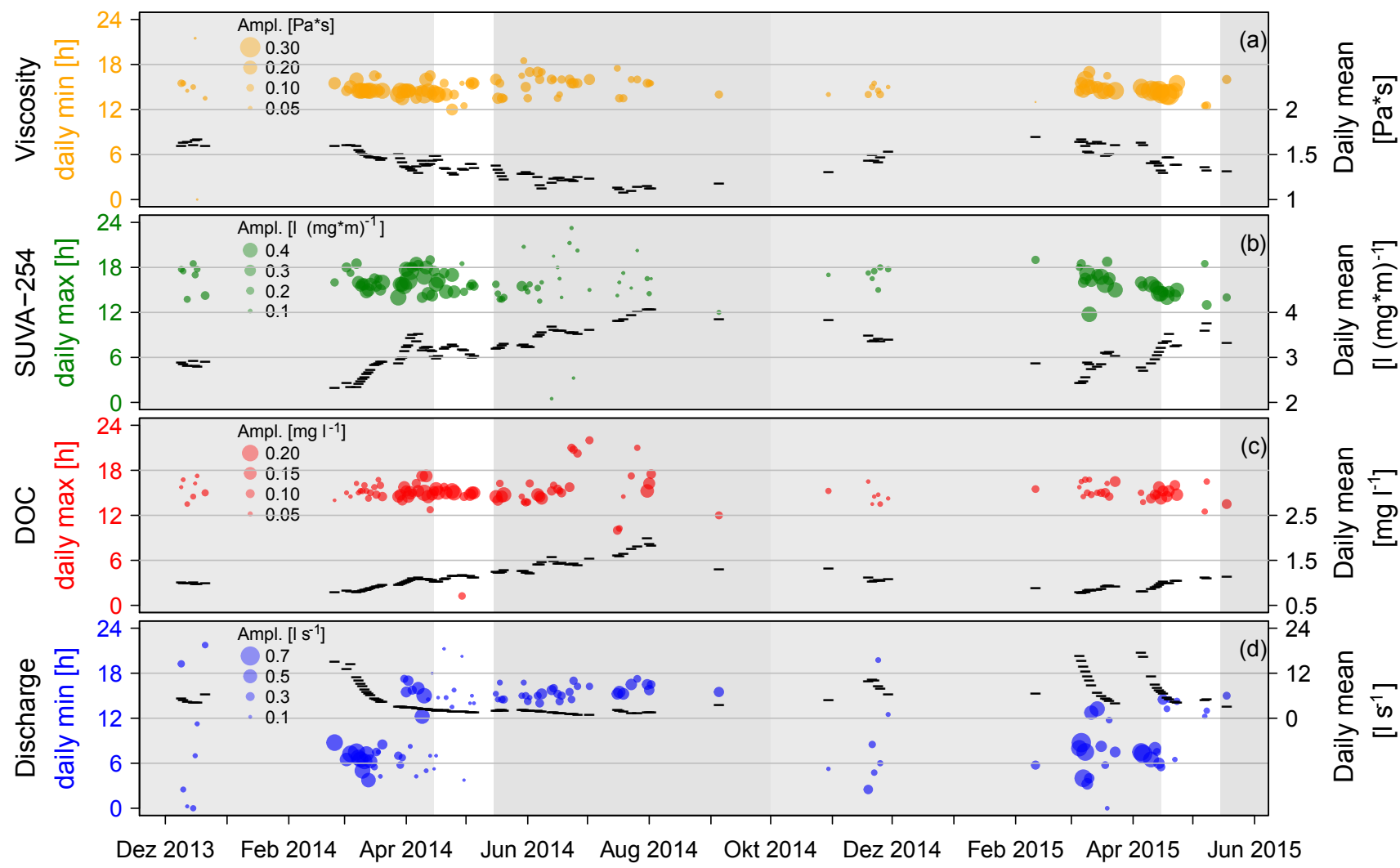

Figure 3. The time of day of the daily minima and maxima of saturated riparian water viscosity, SUVA-254, DOC and discharge over 18 months. Only rainless days with diel fluctuations and without the influence of rainfall-runoff events are represented. The points are scaled by the daily amplitude between the daily minimum and maximum. Black dashes (-) are the daily mean values of the respective variables. Background: dark gray (growing season), light gray (dormant season), white (transition period).

grab samples were measured in the laboratory. To calculate the high-frequency SUVA-254 values of the stream water, we used the in situ spectrometer measurements of DOC and the light absorbance measurements. Due to the $2.5 \mathrm{~nm}$ intervals of the spectrometer, the absorbance data at $254 \mathrm{~nm}$ (A254) were not available. Therefore we calculated A254 as the weighted mean between the absorbance at $252.5 \mathrm{~nm}$ and the absorbance at $255 \mathrm{~nm}$. We eliminated potential outliers in the SUVA-254 time series by applying a $3 \mathrm{~h}$ moving median to the entire time series.

To analyze the diel fluctuations of DOC concentrations, SUVA-254, viscosity and discharge, we selected the days with diel fluctuations during the observation period from December 2013 to May 2015. Days that were influenced by rainfall-runoff events were not included in the analysis. According to this criterion, many short and several longer periods were removed. The two winter seasons and August 2014 were particularly rainy periods. From the remaining days, additional days were removed from further analysis if at least one of the four variables showed unreliable or no values, especially due to problems with the sensors used. A longer period had to be removed in October 2014 for the same reason.
We first analyzed the diel fluctuation patterns of DOC, SUVA-254, viscosity and discharge by comparing their daily minima, maxima and amplitude. For each day with diel fluctuations, we calculated the time of the day when the minima and maxima occurred. The daily amplitude resulted from the difference between the values of the daily maximum and minimum.

For further analysis, we calculated the anomaly of the time series of each of the four variables (DOC, SUVA-254, viscosity and discharge) by subtracting the values of the original time series from those of the daily moving average time series. The daily moving average time series was calculated from the original time series with a window size of $24 \mathrm{~h}$ and no longer showed diel fluctuations. The calculations were based on the time series with $15 \mathrm{~min}$ intervals and resulted in anomaly values for every $15 \mathrm{~min}$.

We studied the anomalies of the four variables by comparing them with the corresponding values at the same time of another variable using scatterplots. With four different variables (DOC, SUVA-254, viscosity, discharge), this resulted in six different combinations. For each combination, linear regressions were calculated separately for each month, for 

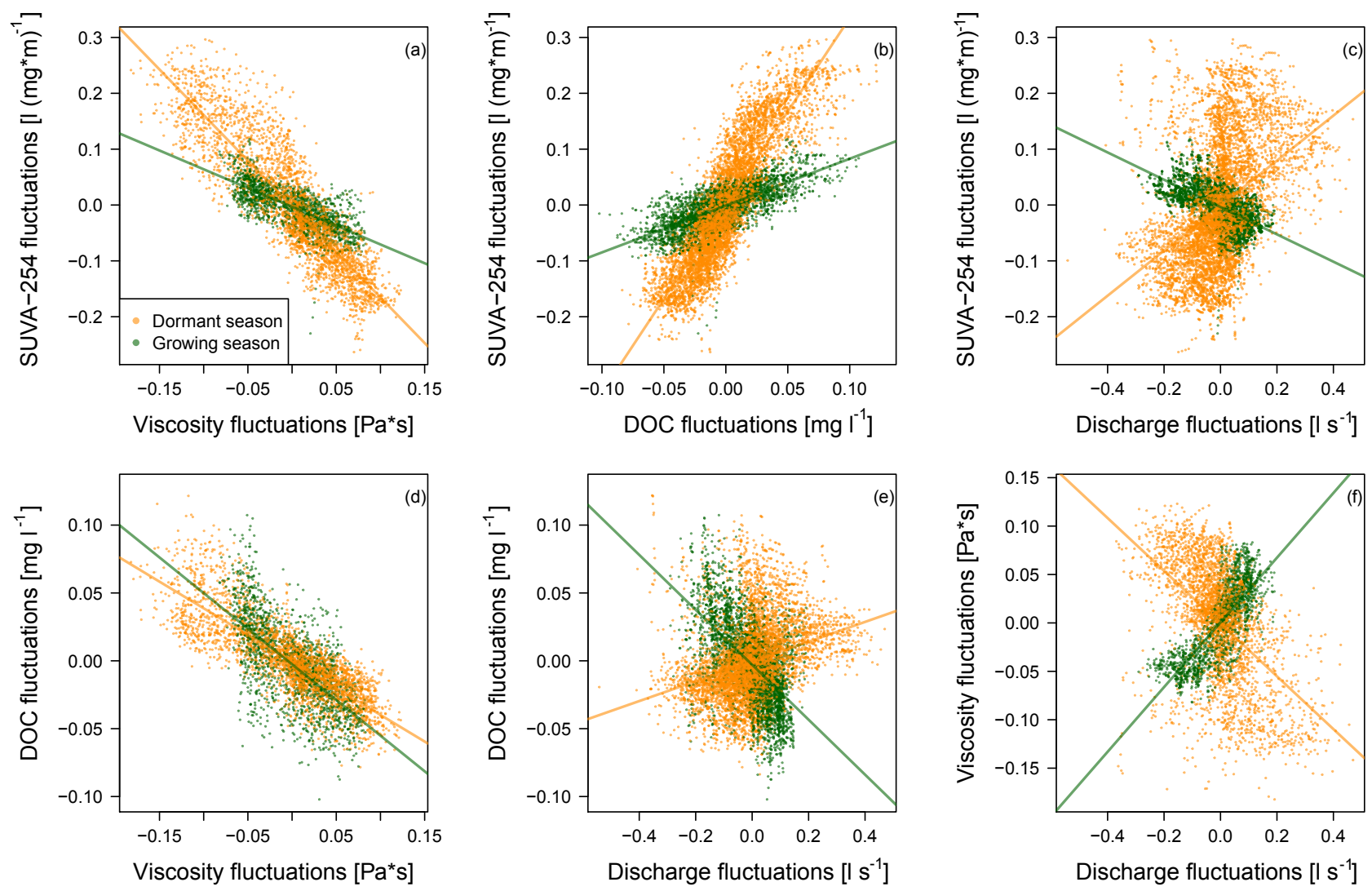

Figure 4. Scatterplots and linear regression between the $15 \mathrm{~min}$ anomalies of the four variables for the growing and dormant period. Only rainless days with diel fluctuations and without the influence of rainfall-runoff events are shown (corresponding to the days in Fig. 3).

the dormant and growing season, and for the entire observation period. Due to the absence of days with diel fluctuations, we could not compute a linear regression for January. We defined the growing season as the period between 15 May and the end of September and the dormant season from the beginning of October until 15 April. To clearly distinguish between the two seasons, we introduced a transition period. As a transition period, we considered the time between midApril and mid-May when not all plants are yet fully active and developed. A transition period was not defined in fall due to the lack of days with diel fluctuations around the end of September and the beginning of October.

\section{Results}

In our long-term high-frequency time series, we observed many days and periods with diel fluctuations in viscosity, SUVA-254, DOC and discharge. In the afternoons of rainless periods during the dormant and the growing season, we observed the diel minima of viscosity and the diel maxima of SUVA-254 and DOC (Fig. 2). During the dormant season, we observed diel discharge minima in the morning, whereas we observed diel discharge minima in the afternoon during the growing season. The diel amplitudes of viscosity, SUVA254 and DOC change in similar ways from one day to the other (Fig. 2e-g).

Over the whole time series of 18 months, the minima in viscosity and the maxima in SUVA-254 and DOC occurred in the afternoon between 14:00 and 18:00 CET for both the growing and the dormant season (Fig. 3a-c). For discharge, the time of the minima switched from early morning in the dormant season to the afternoon in the growing season both in 2014 and 2015 (Fig. 3d). In winter, we only observed a few rainless days outside rainfall-runoff events with diel fluctuations (Fig. 3). During that time (December 2013 and November 2014) no clear diel discharge pattern is visible (Fig. 3d) and the diel amplitudes of all four variables are relatively small. The diel amplitudes of DOC and viscosity stayed relatively constant over the 18 months with the lowest amplitudes of DOC in winter and spring and slightly higher viscosity amplitudes during the growing season than during the dormant season (Fig. 3a, c). The amplitudes of SUVA-254 changed more markedly over the 18 months. SUVA-254 had its highest amplitudes in spring and very low amplitudes in summer (Fig. 3b). 

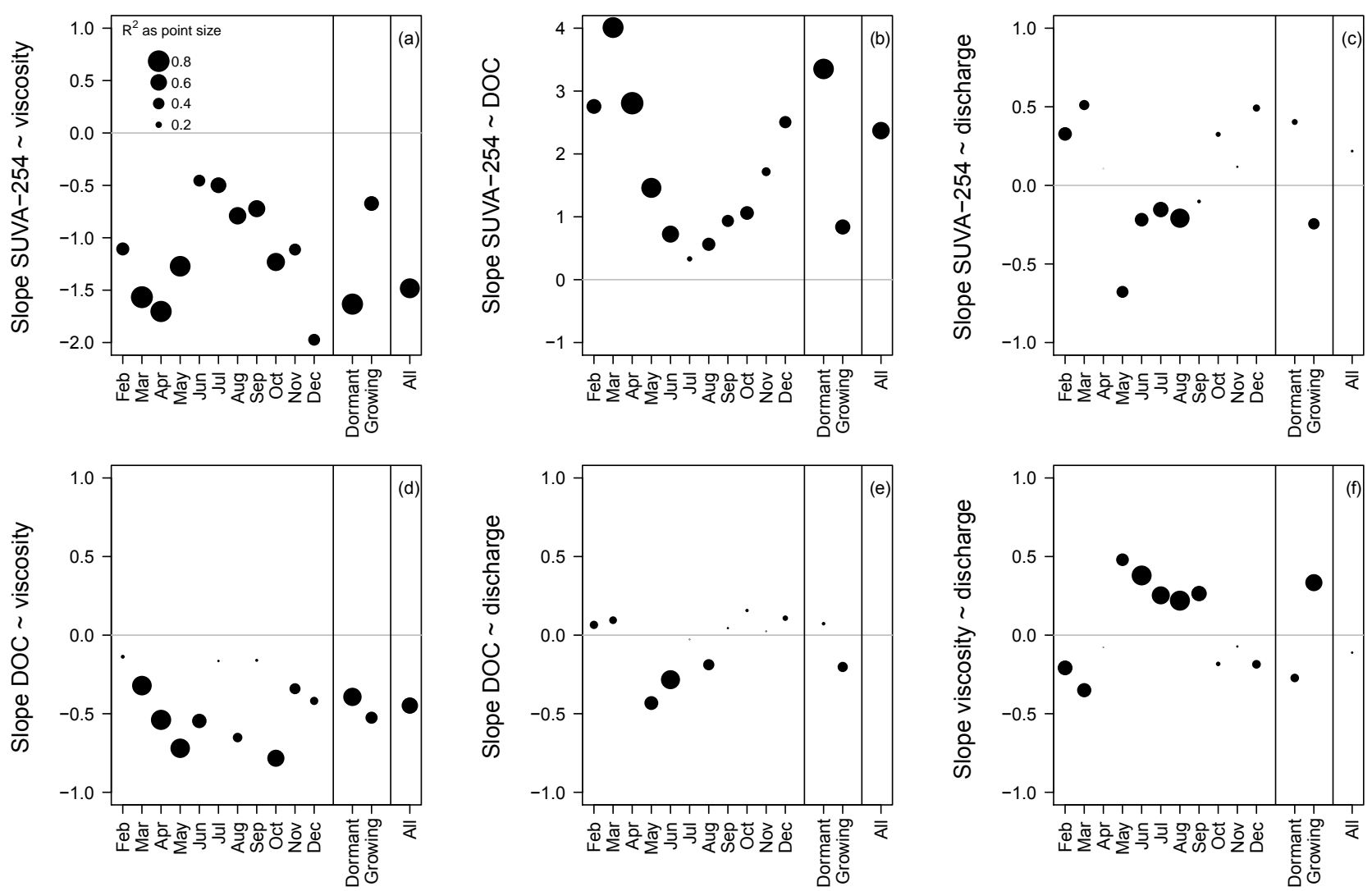

Figure 5. Slope and explained variance $\left(R^{2}\right)$ of the linear regression between the 15 min anomalies of the four variables. Slope and $R^{2}$ are separately calculated for each month, for the dormant and the growing season, and for all values. All the $p$ values are generally highly significant. Only rainless days with diel fluctuations and without the influence of rainfall-runoff events are shown (corresponding to the days in Fig. 3).

Figure 3 shows a seasonal pattern for the daily mean values of all four variables. The viscosity of the saturated riparian water is lower during the growing season than during the dormant season (Fig. 3a), while the mean daily SUVA-254 values and the mean daily DOC concentrations are higher during the growing season than during the dormant season (Fig. 3b, c). The discharge in the Weierbach stream was lower in summer and higher in winter and early spring (Fig. 3d).

After identifying strong similarity in the timing of the diel extreme of viscosity, SUVA-254 and DOC, we analyzed the relationship between the $15 \mathrm{~min}$ anomalies of viscosity, SUVA-254, DOC and discharge. Figures 4 and 5 show a strong linear relationship between SUVA-254 and viscosity, SUVA-254 and DOC, and between DOC and viscosity for the dormant season, the growing season and the entire time series of 18 months with $R^{2}$ larger than 0.6. The slope of the linear regression between the viscosity anomalies and the SUVA-254 anomalies is negative, meaning that the viscosity of the saturated riparian water decreased during the day, while SUVA-254 values increased (Fig. 4a). During the growing season, the slope was less negative than during the dormant season (Figs. $4 \mathrm{a}$ and $5 \mathrm{a}$ ). The values of the slopes show an annual pattern, with the least negative slopes occurring in June and July (Fig. 5a). The slope of regression between the DOC anomalies and the SUVA-254 anomalies is positive (Fig. 4b). An increase in SUVA-254 during the day leads to an increase in DOC concentrations. This relationship is less strong during the growing season, with the smallest slopes occurring in June, July and August (Figs. 4b and $5 \mathrm{~b}$ ). The slope of the regression between viscosity and DOC is negative, meaning that a decrease in viscosity during the day leads to an increase in DOC (Fig. 4d). These negative slopes are relatively constant over the year and between the seasons (Figs. 4d and 5d).

For the combinations that included discharge, we generally observed weaker and more heterogeneous relationships (Figs. 4c, e, f and 5c, e, f). The linear regressions between discharge and SUVA-254, discharge and DOC, and between discharge and viscosity resulted in contrary signs of their slopes between the dormant season and the growing season. Moreover, the $R^{2}$ of the linear regressions in which discharge was involved were generally smaller than for the linear regressions in the absence of discharge (Fig. 5). 

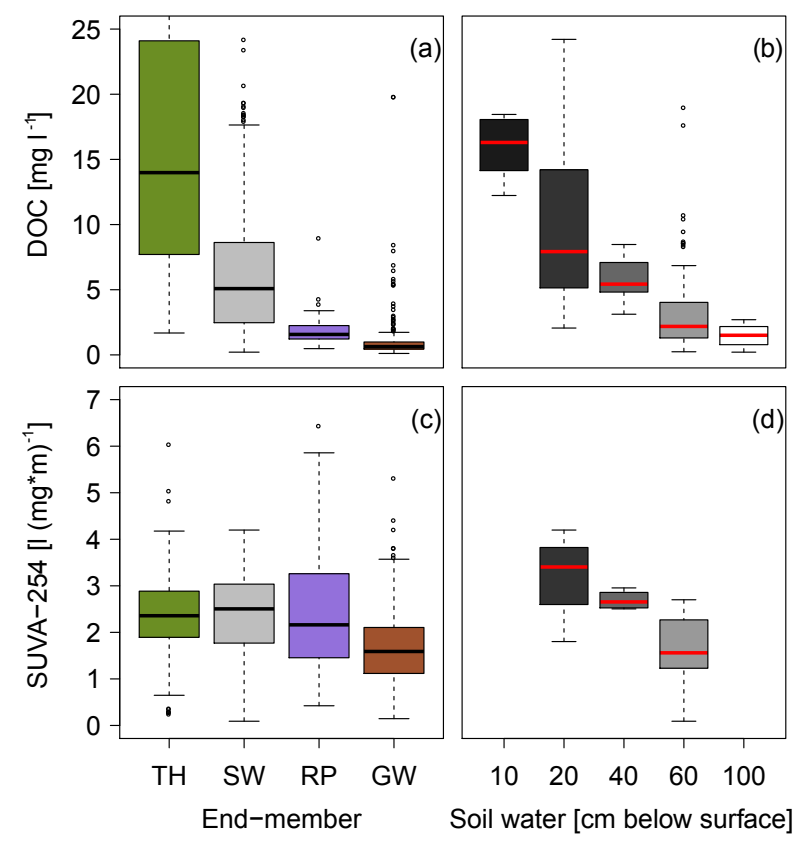

Figure 6. DOC concentrations and SUVA-254 values of the biweekly sampled end-members and the detailed information for soil water at different depths. TH is throughfall, SW is soil water, RP is saturated riparian water and $\mathrm{GW}$ is groundwater.

In addition to the high-frequency instream observations and temperature measurements of the saturated riparian zone, we sampled end-members in the catchment and analyzed them in the laboratory for SUVA-254 and the DOC concentrations. We observed the highest DOC concentrations in throughfall and soil water, lower concentrations in saturated riparian water and the lowest DOC concentrations in the groundwater (Fig. 6a). We found a decrease in DOC concentrations in soil with depth. The highest DOC concentrations were observed in the upper part of the soil profile (Fig. 6b). The SUVA-254 values in soil water behave similarly to the DOC concentrations, having the highest values in the upper part of the soil profile (Fig. 6c). Soil water, throughfall and saturated riparian water have similar SUVA-254 values, while groundwater has the smallest SUVA-254 values (Fig. 6d).

\section{Discussion}

Based on our measurements in the Weierbach catchment, we are convinced that SUVA-254 is a suitable proxy for identifying terrestrial DOC in diel DOC fluctuations. Several studies have already demonstrated that SUVA-254 is a valid index to characterize the origin of DOC (Catalán et al., 2013; Fasching et al., 2016; Lee et al., 2016; Weishaar et al., 2003). We found strong indices in the Weierbach catchment for rising SUVA-254 values serving as a valid index of higher terrestrial DOC input to the stream. Immediately after rain events, discharge, DOC concentrations and SUVA254 rapidly increased. This increase in discharge is related to surface or near-surface runoff processes (Glaser et al., 2016; Klaus et al., 2015). Therefore it is likely that the increase in DOC concentrations was induced by terrestrial DOC input that eventually led to a rise in measured SUVA-254 values. Although our data showed a correlation between absorbance at $254 \mathrm{~nm}$ (A254) and the DOC concentration, an increase in SUVA-254 is not (only) related to an increase in DOC concentration in general, but also to an increase in more aromatic DOC components. According to the measurement methods of the spectrometer, A254 is only one wavelength among several other wavelengths that have been used to calculate the DOC concentration. SUVA-254 is calculated as the absorbance at $254 \mathrm{~nm}$ normalized by the DOC concentration (SUVA-254 = A254/DOC). Consequently, an increase in SUVA-254 is based on an increase in A254 that is larger than the increase in DOC concentration.

We tested our two hypotheses on processes controlling diel DOC fluctuations. For the days with diel fluctuations we generally observed both DOC and SUVA-254 maxima in the afternoon. Thus we could reject our first hypothesis that microbial autochthonous instream processes are the dominant control on the DOC maxima in the afternoon. However, we need to keep in mind that biological processes that recycle DOC are manifold, leading to complex antagonistic results, and that SUVA-254 is only a proxy for the complex composition of DOC computed from absorbance properties. Nevertheless, the increased SUVA-254 values in the afternoon provide strong support for our second hypothesis that the DOC maxima in the afternoon are triggered by an increase in terrestrial DOC input to the stream in the afternoon. Additional support for the second hypothesis is that the high-frequency anomalies of DOC and SUVA-254 behave in a similar way as suggested by the good fit of the regression between those two variables. Additionally, the SUVA-254 values and DOC concentrations of the end-members are a strong indicator of the origin of the stream water in the afternoon (when SUVA254 and DOC are on the rise). For both DOC and SUVA-254, soil water and saturated riparian water had higher values than groundwater, and the values in the topsoil were higher than in the subsoil for both variables. Rejecting the first hypothesis and supporting the second hypothesis does not imply that biological processes were absent. Yet, these processes were not the dominant control for the diel DOC fluctuations (Fig. 7).

Our study provides strong experimental evidence for viscosity-controlled diel DOC fluctuations in the Weierbach. Previous work by Schwab et al. (2016) in the Weierbach catchment has shown that an increase in riparian water temperature during the day led to a decrease in riparian water viscosity and subsequently to an increase in hydraulic conductivity. This viscosity effect resulted in an increased inflow of riparian groundwater to the stream in the afternoon from the topsoil of the saturated riparian zone to the stream. 

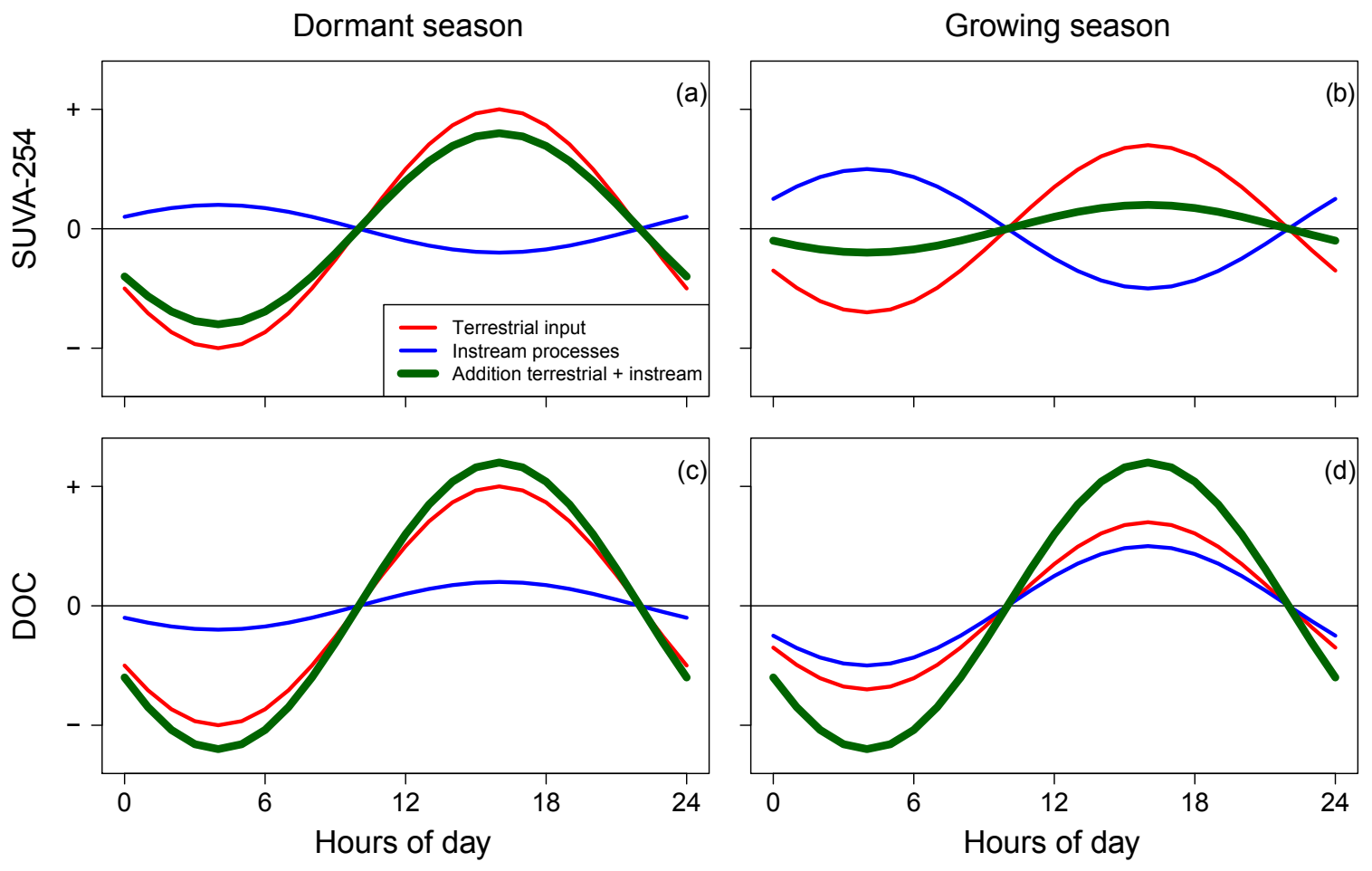

Figure 7. Perceptual understanding of the diel SUVA-254 and DOC fluctuations and their dependence on instream processes or terrestrial input and the resulting superposition of both processes.

The timing of the daily minima of viscosity in the afternoon is consistent with the timing of the daily maxima of DOC and SUVA-254. Besides the timing of the viscosity minima, the high-frequency anomalies provide another solid indication that the viscosity effect triggers an increased inflow of terrestrial DOC to the stream in the afternoon. The strong regression between the viscosity and the SUVA-254 anomalies, especially the regression between the viscosity and the DOC anomalies, showed that viscosity, SUVA-254 and DOC had very similar diel dynamics.

The regressions between the discharge anomalies and the anomalies of viscosity, SUVA-254 and DOC resulted in different slope directions and values depending on the season. This behavior can be explained by the existence of two different opposing processes that control the diel discharge fluctuations: the viscosity effect during the dormant season and evapotranspiration during the growing season (Schwab et al., 2016). However, we believe that the viscosity effect is always present, even when its effect on diel discharge fluctuations is hidden by the stronger counteracting influence of evapotranspiration during the growing season. As the viscosity effect is present all year long, it can control the diel fluctuations of DOC concentration and SUVA-254 values both during the dormant and the growing seasons. Evapotranspiration cannot hide the influence of the viscosity effect on diel DOC and SUVA-254 fluctuations during the growing season as evap- otranspiration and viscosity impact different water sources with dissimilar DOC concentrations and SUVA-254 values. While the viscosity effect is only present in the topsoil of the riparian zone, the plants transpire water from deeper soil depths (Bond et al., 2002; Schwab et al., 2016). The upper parts of the soil had especially high SUVA-254 and DOC concentration values.

There are different models for simulating autochthonous DOC dynamics (Fasching et al., 2016; Worrall and Moody, 2014). However, these models are partly contradictory and no state-of-the-art model has been established so far. In addition, we did not have all the data required to run these models. Consequently, we did not simulate the autochthonous DOC dynamics. However, we developed a perceptual model to explain the observed diel DOC and SUVA-254 anomalies, depending on instream processes and terrestrial input (Fig. 7). The conceptual model follows the main results of Fasching et al. (2016), stipulating that instream DOC production is higher with increasing stream water temperature and increasing photosynthetically active radiation (PAR). With the perceptual model illustrated in Fig. 7, we can also explain the observed smaller slopes resulting from the regression between the SUVA-254 and DOC anomalies during the growing season. The amplitudes of the diel DOC anomalies stayed relatively constant over the whole year, while the diel amplitudes of SUVA-254 decreased during the growing sea- 
son. We argue that the increasing importance of instream processes during the growing season leads to a decrease in SUVA-254.

In our perceptual model (Fig. 7), the diel SUVA-254 fluctuations resulting from instream processes show an opposite pattern compared to the diel SUVA-254 fluctuations resulting from terrestrial DOC input. This can be explained by differences in the aromaticity of the DOC of the two processes. Depending on the magnitude of the two processes, the resulting superposition of both processes may or may not change the diel pattern. As a consequence of the increasing stream water temperature and PAR in summer, SUVA-254 fluctuations resulting from instream processes are much higher during the growing season than during the dormant season (Fig. 7a, b; Fasching et al., 2016). On the other hand, the diel SUVA-254 fluctuations resulting from terrestrial DOC input triggered by viscosity effects are smaller during the growing season due to a decrease in the viscosity fluctuations in summer (Schwab et al., 2016). By overlaying the instream and the terrestrial effect on SUVA-254, the resulting diel SUVA-254 fluctuations are higher in the dormant season than in the growing season.

Contrary to the SUVA-254 fluctuations, the diel DOC fluctuations resulting from instream processes and terrestrial input are in phase. They have their maxima in the afternoon when the stream water temperature and the PAR (influencing the instream processes) are at their maxima and the riparian water viscosity (influencing the terrestrial input) has its minima. During the growing season (Fig. 7d), the diel DOC fluctuations induced by instream processes are higher than during the dormant season and the DOC fluctuations resulting from terrestrial input are smaller (smaller viscosity fluctuations) than during the dormant season (Fig. 7c). Consequently, overlaying both effects results in similar DOC fluctuations during the growing and the dormant seasons (Fig. 7c, d). In other catchments the relative proportion of the different processes is probably different, resulting in other overall diel fluctuations.

In addition to the diel fluctuations, we observed a seasonal pattern in the daily mean values of SUVA-254 and DOC concentrations. In the Weierbach stream we observed higher SUVA-254 values and DOC concentrations during the low flow periods compared to high flow periods, while Lee et al. (2016) and Fasching et al. (2016) described lower SUVA254 values during dry and baseflow conditions (Fig. 3). This could likely be explained by different flow paths of the water contributing to streamflow. During summer low flow, we suspect that only a few source areas in the riparian zone contribute to streamflow. Those riparian source areas have higher SUVA-254 values and DOC concentrations (Fig. 6). During periods with higher discharge, especially in winter and early spring, a dilution effect leads to decreasing SUVA-254 values and DOC concentrations. Larger areas with lower SUVA254 values and DOC concentrations contribute to streamflow. During those wet conditions, subsurface flow, whose SUVA254 and DOC signature is represented by the shallow ground- water end-member (Fig. 6), generated a large part of the discharge.

\section{Conclusions}

We observed diel DOC fluctuations in the Weierbach catchment over a complete year during periods that were not affected by rainfall-runoff processes. By means of the SUVA254 index serving as an indicator for DOC aromaticity, we found that an increased input of DOC with terrestrial origin was responsible for the peak in DOC concentrations in the afternoon. Higher SUVA-254 values indicate a higher aromaticity of DOC and therefore an increase in DOC from terrestrial (allochthonous) sources. We could explain the increased input of terrestrial DOC in the afternoon with the viscosity effect. Water passing the saturated riparian zone before entering the stream is heated in the riparian zone during the day. Warmer water has a decreased viscosity and therefore the hydraulic conductivity increases. Consequently, more water from near-surface zones that are rich in terrestrial DOC is entering the stream in the afternoon. Our study described a new process that can explain diel DOC fluctuations in streams. We argue that the analysis of diel DOC fluctuations should not only focus on instream processes, but also on surface areas in the vicinity of the stream. Moreover, viscosity-driven diel hydrological flow processes have to be taken into account to understand diel DOC dynamics in streams.

For further studies, we suggest combining the UV-Vis spectrometer measurements with fluorescence spectrometry measurements to gain even more detailed information about the origin of the DOC. Furthermore, a more detailed insight into the instream DOC processes would be an interesting aspect of future research. Oxygen probes could be very helpful for studying metabolic activity in the Weierbach stream. Additionally, we hope that our study can raise the awareness of the viscosity-driven input of terrestrial DOC in explaining diel DOC fluctuations in stream water. We believe that this effect can be also detected in other catchments, but depends on the catchment-specific interplay of both interacting processes.

Data availability. The underlying research data are available upon request by emailing Michael Schwab (mschwab@wmo.int) or Luxembourg Institute of Science and Technology (info@list.lu).

Competing interests. The authors declare that they have no conflict of interest.

Acknowledgements. We acknowledge the FNR (Fonds National de la Recherche Luxembourg) for having funded this research through an AFR PhD grant (6931545). Additional funding was provided 
through the FNR-DFG CAOS-2 project (INTER/DFG/14/02) and the FNR-DFG-funded CAOS project (INTER/DFG/11/01). We also thank Jean François Iffly, François Barnich and Jérôme Juilleret for their support during field activities and in the laboratory. Special thanks go to Christophe Hissler, who provided us with the biweekly end-member dataset that was acquired during the project FNR/CORE/SOWAT (C10/SR/799842).

Edited by: Tom J. Battin

Reviewed by: two anonymous referees

\section{References}

Battin, T. J., Kaplan, L. A., Findlay, S., Hopkinson, C. S., Marti, E., Packman, A. I., Newbold, J. D., and Sabater, F.: Biophysical controls on organic carbon fluxes in fluvial networks, Nat. Geosci., 1, 95-100, https://doi.org/10.1038/ngeo101, 2008.

Bond, B. J., Jones, J. A., Moore, G., Phillips, N., Post, D., and McDonnell, J. J.: The zone of vegetation influence on baseflow revealed by diel patterns of streamflow and vegetation water use in a headwater basin, Hydrol. Process., 16, 1671-1677, https://doi.org/10.1002/hyp.5022, 2002.

Catalán, N., Obrador, B., Felip, M., and Pretus, J. L.: Higher reactivity of allochthonous vs. autochthonous DOC sources in a shallow lake, Aquat. Sci., 75, 581-593, https://doi.org/10.1007/s00027013-0302-y, 2013.

Chittoor Viswanathan, V., Molson, J., and Schirmer, M.: Does river restoration affect diurnal and seasonal changes to surface water quality? A study along the Thur River, Switzerland, Sci. Total Environ., 532, 91-102, https://doi.org/10.1016/j.scitotenv.2015.05.121, 2015.

Dawson, J. J. ., Bakewell, C., and Billett, M.: Is in-stream processing an important control on spatial changes in carbon fluxes in headwater catchments?, Sci. Total Environ., 265, 153-167, https://doi.org/10.1016/S0048-9697(00)00656-2, 2001.

Fasching, C., Ulseth, A. J., Schelker, J., Steniczka, G., and Battin, T. J.: Hydrology controls dissolved organic matter export and composition in an Alpine stream and its hyporheic zone, Limnol. Oceanogr., 61, 558-571, https://doi.org/10.1002/lno.10232, 2016.

Glaser, B., Klaus, J., Frei, S., Frentress, J., Pfister, L., and Hopp, L.: On the value of surface saturated area dynamics mapped with thermal infrared imagery for modeling the hillsloperiparian-stream continuum, Water Resour. Res., 52, 8317-8342, https://doi.org/10.1002/2015WR018414, 2016.

Hanley, K. W., Wollheim, W. M., Salisbury, J., Huntington, T., and Aiken, G.: Controls on dissolved organic carbon quantity and chemical character in temperate rivers of North America, Global Biogeochem. Cy., 27, 492-504, https://doi.org/10.1002/gbc.20044, 2013.

Hood, E., Gooseff, M. N., and Johnson, S. L.: Changes in the character of stream water dissolved organic carbon during flushing in three small watersheds, Oregon, J. Geophys. Res., 111, G01007, https://doi.org/10.1029/2005JG000082, 2006.

Klaus, J., Wetzel, C. E., Martínez-Carreras, N., Ector, L., and Pfister, L.: A tracer to bridge the scales: on the value of diatoms for tracing fast flow path connectivity from headwaters to meso-scale catchments, Hydrol. Process., 29, 5275-5289, https://doi.org/10.1002/hyp.10628, 2015.

Lee, M.-H., Payeur-Poirier, J.-L., Park, J.-H., and Matzner, E.: Variability in runoff fluxes of dissolved and particulate carbon and nitrogen from two watersheds of different tree species during intense storm events, Biogeosciences, 13, 5421-5432, https://doi.org/10.5194/bg-13-5421-2016, 2016.

Martínez-Carreras, N., Wetzel, C. E., Frentress, J., Ector, L., McDonnell, J. J., Hoffmann, L., and Pfister, L.: Hydrological connectivity inferred from diatom transport through the riparian-stream system, Hydrol. Earth Syst. Sci., 19, 3133-3151, https://doi.org/10.5194/hess-19-3133-2015, 2015.

McLaughlin, C. and Kaplan, L. A.: Biological lability of dissolved organic carbon in stream water and contributing terrestrial sources, Freshw. Sci., 32, 1219-1230, https://doi.org/10.1899/12-202.1, 2013.

Minor, E. C., Swenson, M. M., Mattson, B. M., and Oyler, A. R.: Structural characterization of dissolved organic matter: a review of current techniques for isolation and analysis, Environ. Sci.Pro. Imp., 16, 2064-79, https://doi.org/10.1039/c4em00062e, 2014.

Moragues-Quiroga, C., Juilleret, J., Gourdol, L., Pelt, E., Perrone, T., Aubert, A., Morvan, G., Chabaux, F., Legout, A., Stille, P., and Hissler, C.: Genesis and evolution of regoliths: Evidence from trace and major elements and $\mathrm{Sr}-\mathrm{Nd}-\mathrm{Pb}-\mathrm{U}$ isotopes, CATENA, 149, 185-198, https://doi.org/10.1016/j.catena.2016.09.015, 2017.

Nimick, D. A., Gammons, C. H., and Parker, S. R.: Diel biogeochemical processes and their effect on the aqueous chemistry of streams: A review, Chem. Geol., 283, 3-17, https://doi.org/10.1016/j.chemgeo.2010.08.017, 2011.

Parker, S. R., Poulson, S. R., Smith, M. G., Weyer, C. L., and Bates, K. M.: Temporal Variability in the Concentration and Stable Carbon Isotope Composition of Dissolved Inorganic and Organic Carbon in Two Montana, USA Rivers, Aquat. Geochem., 16, 6184, https://doi.org/10.1007/s10498-009-9068-1, 2010.

Pfister, L., Martínez-Carreras, N., Hissler, C., Klaus, J., Carrer, G. E., Stewart, M. K., and McDonnell, J. J.: Bedrock geology controls on catchment storage, mixing, and release: A comparative analysis of 16 nested catchments, Hydrol. Process., 31, 18281845, https://doi.org/10.1002/hyp.11134, 2017.

Ruhala, S. S. and Zarnetske, J. P.: Using in-situ optical sensors to study dissolved organic carbon dynamics of streams and watersheds: A review, Sci. Total Environ., 575, 713-723, https://doi.org/10.1016/j.scitotenv.2016.09.113, 2017.

Saraceno, J. F., Pellerin, B. A., Downing, B. D., Boss, E., Bachand, P. A. M., and Bergamaschi, B. A.: High-frequency in situ optical measurements during a storm event: Assessing relationships between dissolved organic matter, sediment concentrations, and hydrologic processes, J. Geophys. Res., 114, G00F09, https://doi.org/10.1029/2009JG000989, 2009.

Schwab, M., Klaus, J., Pfister, L., and Weiler, M.: Diel discharge cycles explained through viscosity fluctuations in riparian inflow, Water Resour. Res., 52, 8744-8755, https://doi.org/10.1002/2016WR018626, 2016.

Schwab, M. P., Klaus, J., Pfister, L., and Weiler, M.: How runoff components affect the export of DOC and nitrate: a long-term and high-frequency analysis, Hydrol. Earth Syst. Sci. Discuss., https://doi.org/10.5194/hess-2017-416, in review, 2017. 
Spencer, R. G. M., Pellerin, B. A., Bergamaschi, B. A., Downing, B. D., Kraus, T. E. C., Smart, D. R., Dahlgren, R. A., and Hernes, P. J.: Diurnal variability in riverine dissolved organic matter composition determined byin situ optical measurement in the San Joaquin River (California, USA), Hydrol. Process., 21, 31813189, https://doi.org/10.1002/hyp.6887, 2007.

Spencer, R. G. M., Butler, K. D., and Aiken, G. R.: Dissolved organic carbon and chromophoric dissolved organic matter properties of rivers in the USA, J. Geophys. Res.-Biogeo., 117, 21562202, https://doi.org/10.1029/2011JG001928, 2012.

Tipler, P. A. and Mosca, G.: Physics for Scientists and Engineers, 6th Edn., W. H. Freeman \& Company, New York, NY, USA, 2008.

Tunaley, C., Tetzlaff, D., and Soulsby, C.: Scaling effects of riparian peatlands on stable isotopes in runoff and DOC mobilization, J. Hydrol., 549, 220-235, https://doi.org/10.1016/j.jhydrol.2017.03.056, 2017.

Vogel, H.: Das Temperaturabhängigkeitsgesetz der Viscosität von Flüssigkeiten, Phys. Z., 22, 645-646, 1921.
Weishaar, J. L., Aiken, G. R., Bergamaschi, B. A., Fram, M. S., Fujii, R., and Mopper, K.: Evaluation of Specific Ultraviolet Absorbance as an Indicator of the Chemical Composition and Reactivity of Dissolved Organic Carbon, Environ. Sci. Technol., 37, 4702-4708, https://doi.org/10.1021/es030360x, 2003.

Worrall, F. and Moody, C. S.: Modeling the rate of turnover of DOC and particulate organic carbon in a UK, peathosted stream: Including diurnal cycling in short-residence time systems, J. Geophys. Res.-Biogeo., 119, 1934-1946, https://doi.org/10.1002/2014JG002671, 2014.

Worrall, F., Howden, N. J. K., and Burt, T. P.: Understanding the diurnal cycle in fluvial dissolved organic carbon - The interplay of in-stream residence time, day length and organic matter turnover, J. Hydrol., 523, 830-838, https://doi.org/10.1016/j.jhydrol.2015.01.075, 2015. 